\title{
Synthesis, characterization and evaluation of polyacrylamide graft starch/clay nanocomposite hydrogel system for enhanced oil recovery
}

\author{
Rituraj Singh $^{1} \cdot$ Vikas Mahto $^{1}$
}

Received: 6 August 2016/Published online: 7 September 2017

(c) The Author(s) 2017. This article is an open access publication gel systems under reservoir conditions. Hence, this gel system may be suitable in the water shutoff treatments required for enhanced oil recovery from oilfields.

Keywords Nanocomposite - Graft polymer · Nanoclay · Hydrogel · Water shutoff

\section{Introduction}

Water control is a key issue in most of hydrocarbon reservoirs (Liu et al. 2010; Salehi et al. 2014; Yadav and Mahto 2013a). Polymer gels are widely used to control water production by blocking the high-permeability zones in heterogeneous mature reservoirs and then diverting the water to the low-permeability zones during enhanced oil recovery operations. Polymer gel is very cost-effective as it does not require a work over rig and it can control water production for a long period of time (Elsharafi and Bai 2012, 2016; Yadav and Mahto 2013b; Zhao et al. 2011). Synthetic polymers and biopolymers are two main types of polymers which have been used in reservoirs since the 1950s. Synthetic polymers with crosslinkers are applicable at high temperatures as well as a wide range of $\mathrm{pH}$ and biopolymers are stable at high temperatures and salinity, but they are much expensive and susceptible to bacterial attack (Hoefner et al. 1992; Singh et al. 2015; Strom et al. 1991; Vossoughi and Buller 1991).

Recently, graft copolymers of natural polysaccharides and synthetic polymer have been reported to enhance the physical properties of polymers. Graft copolymerization of natural polymers with functional synthetic polymers gives modified products having a wide range of applications due to combining in one molecule the desired properties of both

Edited by Yan-Hua Sun 
the natural polymer and the synthetic polymer (Behari et al. 2001; Biswal and Singh 2004; Maia et al. 2012; Pandey and Mishra 2011). Graft copolymerization is an easy method to modify the structure of natural polymers and thus makes them suitable for various applications such as flocculants (Ghorai et al. 2013; Sen et al. 2011), controlled drug release (Namazi and Belali 2015) and petroleum recovery treatments (Singh and Mahto 2016b; Song and Zhang 2007) of mature reservoirs. The graft polymers have the advantage of associating common properties such as high thermal and shear stability because of the attachment of polyacrylamide chains onto the rigid polysaccharide backbone. These graft polymers react with different crosslinkers to form three-dimensional (3D) hydrophilic network hydrogel. Starch is a potentially useful material because of its natural abundance and low cost. The demand for starch graft copolymers is great in industry due to their low cost and biodegradable properties making them environmentally friendly. Starch graft copolymers have become the focus for the preparation of inorganic-organic superabsorbent polymer gel because of their environmental acceptability and the crosslinked system (hydrogel) has high thermal stability, salt-resistant and long-term stability (Qiao and Zhu 2010). However, these hydrogels mainly do not possess adequate strength. Introducing nanoclay into hydrogels to prepare nanocomposite hydrogels may be considered as a useful method to improve the properties of hydrogels. These improvements can include high moduli, increased thermal stability and mechanical strength as well as high extensibility and elasticity compared to the graft polymers (Aalaie and Rahmatpour 2008; Aalaie and Vasheghani-Farahani 2012; Moghadam et al. 2012; Mohammadi et al. 2015).

Several researchers have focused on studying nanocomposite hydrogels suitable for enhanced oil recovery applications due to their characteristic network structures (Aalaie and Rahmatpour 2008; Aalaie et al. 2008; Zolfaghari et al. 2006). These nanocomposite hydrogels mainly consist of polymer chains connecting neighboring clay sheets (Aalaie and Rahmatpour 2008). Zolfaghari et al. (2006) prepared hydrogels based on partially hydrolyzed polyacrylamide (PHPA), montmorillonite (nanoclay) and $\mathrm{Cr}$ (III) (as a crosslinker). They showed that the nanocomposite gels prepared with a low crosslinker concentration had high gel strength and modulus, which results in high syneresis at high temperatures compared with the unfilled polyacrylamide gel. Aalaie et al. (2008) prepared hydrogels by crosslinking sulfonated polyacrylamide/sodium montmorillonite with chromium triacetate (metallic crosslinker). They investigated the effects of montmorillonite on gelation behavior and the ionic strength on the swelling behavior of sulfonated polyacrylamide nanocomposite hydrogels in electrolyte solutions. They found that nanocomposite gels had higher resistance against syneresis in electrolyte solutions compared with the conventional crosslinked hydrogels. Tongwa et al. (2013) prepared a nanocomposite hydrogel using anionic partially hydrolyzed polyacrylamide and laponite (nanoclay) with absence of any crosslinkers. They reported that the clay concentration had a significant effect on the gel strength of the nanocomposite hydrogel. They also found that the nanocomposite hydrogel without any crosslinker exhibited excellent tensile mechanical properties. However, these developed nanocomposite gels had higher concentrations of polymer and crosslinker which would result in a reduction in the mechanical toughness and an increase in the syneresis of gels. These problems may lead to decreasing the effectiveness of these gels for longer duration in the formation.

The motivation of this research is to develop a novel graft polymer nanocomposite hydrogel to overcome the limitations of the conventional gels used in oilfields. The graft polymer nanocomposite hydrogel system may be prepared at low polymer and crosslinker concentrations and have higher gel strength and required longer gelation time than the conventional gel systems.

In this research, a novel polyacrylamide graft starch/clay nanocomposite hydrogel was prepared and characterized by FTIR, XRD, TEM, TGA and FESEM. Then, the effects of different parameters such as polymer concentration, crosslinker concentration and temperature on the gelation rate were investigated to determine an optimum gel formation. Finally, the water control performance of the graft polymer nanocomposite gel was thoroughly investigated by sand pack flooding at $90{ }^{\circ} \mathrm{C}$ for its suitability for enhanced oil recovery application.

\section{Experimental}

\subsection{Reagents and materials}

Acrylamide (AAm), potassium persulphate (extra pure), acetone, starch and sodium chloride $(\mathrm{NaCl})$ were procured from E. Merck, Germany. Hydrophilic sodium montmorillonite (MMT) was purchased from Sigma-Aldrich, USA. Chromium (III) acetate was procured from CDH Chemicals Ltd., New Delhi, India. Hydrochloric acid $(\mathrm{HCl})$ and sodium hydroxide $(\mathrm{NaOH})$ purchased from Merck Pvt. Ltd., Mumbai, India, were used to adjust $\mathrm{pH}$ of solutions.

\subsection{Gelatinization of starch}

Firstly, starch was dried in a hot air oven at $60{ }^{\circ} \mathrm{C}$ for at least $4 \mathrm{~h}$ and then the required amount $(2 \mathrm{~g})$ of starch was added to a 500-mL three-necked round bottom flask equipped with a magnetic stirrer. This flask was kept in an oil bath maintained at $60{ }^{\circ} \mathrm{C}$ as the swelling temperature of 
starch is $55{ }^{\circ} \mathrm{C}$ (Nakason et al. 2010). Nitrogen gas was purged thoroughly into the flask and stirred for at least $5 \mathrm{~min}$ to eliminate oxygen gas. Distilled water was then added at a $1: 1(\mathrm{w} / \mathrm{w})$ ratio of starch and water to the flask and stirred at $60^{\circ} \mathrm{C}$ for half an hour to form gelatinized starch. The gelatinized starch was then cooled at room temperature $\left(25^{\circ} \mathrm{C}\right)$ (Nakason et al. 2010).

\subsection{Synthesis of the graft polymer nanocomposite}

The gelatinized starch $(\mathrm{St})$ graft polyacrylamide sodium montmorillonite nanocomposite (PAAm-g-St/MMT) was synthesized by the free radical polymerization technique in an inert atmosphere of nitrogen using potassium persulphate (KPS) as an initiator (Ghorai et al. 2013; Mansoori et al. 2010). At first, MMT nanoparticles were dispersed in $150 \mathrm{~mL}$ double distilled water and stirred to form an aqueous dispersion of MMT nanoparticles in an ultrasonic bath $(400 \mathrm{rpm})$ at room temperature until the full dispersion of MMT was obtained. Different MMT to monomer ratios $(0.0005-0.0030)$ were used to obtain completely dispersed polymer matrix with MMT nanoparticles. The gelatinized starch was added to a 500-mL three-necked round bottom flask equipped with a magnetic stirrer and a reflux condenser. The amount of gelatinized starch $(1.0-3.0 \mathrm{~g})$ was varied to produce the optimum grade of the nanocomposite. This flask was kept in an oil bath maintained at $60{ }^{\circ} \mathrm{C}$. The dispersed solution of MMT was then added drop wise to the flask and allowed to mix until the mixture was homogenized. After that, $20 \mathrm{~mL}$ aqueous solution containing $0.28 \mathrm{~mol}$ acrylamide monomer was poured into the flask having the dispersed starch-montmorillonite solution and was stirred for $45 \mathrm{~min}$. After proper mixing, $5 \mathrm{~mL}$ potassium persulphate solution $\left(2.56 \times 10^{-5} \mathrm{~mol}\right)$ was added slowly and the reaction was continued for another $1.5 \mathrm{~h}$ at the same stirring speed and temperature. The mixture was purged with nitrogen gas continuously during the reaction. The synthesized product was precipitated and washed several times with acetone to remove any impurities and dried overnight at $60{ }^{\circ} \mathrm{C}$. Starch (St) graft polyacrylamide (PAAm-g-St) was also synthesized by the same procedure as above in the absence of nanoclay. The high amount of MMT (>2000 ppm) hindered the polymerization process, and the high amount of starch $(>2.0 \mathrm{~g})$ resulted in a low product yield. Finally, $2000 \mathrm{ppm}$ MMT and $2.0 \mathrm{~g}$ starch were used for the synthesis of graft nanocomposite.

\subsection{Preparation of the graft polymer nanocomposite hydrogel}

Initially, the stock dispersion of synthesized graft polymer nanocomposite $(0.4 \mathrm{wt} \%, 0.5 \mathrm{wt} \%, 0.6 \mathrm{wt} \%, 0.7 \mathrm{wt} \%$ and
$0.8 \mathrm{wt} \%$ ) was prepared by gradual addition of the polymer to the $\mathrm{NaCl}$ solution $(30,000 \mathrm{ppm})$ and aged without stirring at room temperature for $24 \mathrm{~h}$ until a homogeneous dispersion was obtained. Fresh crosslinker solutions $(0.2 \mathrm{wt} \%, 0.4 \mathrm{wt} \%, 0.5 \mathrm{wt} \%, 0.6 \mathrm{wt} \%, 0.7 \mathrm{wt} \%$ and $0.8 \mathrm{wt} \%)$ were prepared by adding chromium(III) acetate to brine. Then, the crosslinker solution and the graft nanocomposite dispersion were mixed and homogenized by constant stirring using a magnetic stirrer to obtain the gelant solution. The $\mathrm{pH}$ of gelant was maintained using $\mathrm{NaOH}$ and $\mathrm{HCl}$ solutions. The obtained gelant solutions were taken in glass tubes and kept in a hot air oven at the desired temperatures $\left(60,70,80,90,100\right.$ and $\left.110^{\circ} \mathrm{C}\right)$ for gelation, and we inspected visually the gel formation at regular intervals.

\subsection{Characterization of graft polymer nanocomposite (PAAm-g-St/MMT) and graft polymer nanocomposite hydrogel (PAAm-g-St/ MMT hydrogel)}

X-ray diffraction (XRD), Fourier transform infrared (FTIR) spectrometric analysis and field-emission scanning electron microscopy (FESEM) were conducted to reveal the formation of nanocomposites. Before analysis, the samples were dried in a vacuum oven (150 $\mathrm{mmHg}$ absolute) at $70{ }^{\circ} \mathrm{C}$ for $24 \mathrm{~h}$ to remove water. Wide angle XRD measurements were performed at room temperature with a PAN analytical X-ray diffractometer using $\mathrm{Cu}$-filtered $K \alpha$ radiation $\left(\lambda_{1}=1.5405, \lambda_{2}=1.5444\right)$ at a voltage of $45 \mathrm{kV}$ and current of $40 \mathrm{~mA}$. The XRD patterns were obtained in $2 \theta$ ranges from 5 to $11^{\circ}$ with a step size of $0.02^{\circ}$.

FTIR spectrometric analysis was performed over a range $450-4000 \mathrm{~cm}^{-1}$ in the solid state, using $\mathrm{KBr}$ pellets using a Perkin Elmer FTIR spectrometer (model Spectrum Two, USA).

The surface morphology of platinum-coated starch, polyacrylamide (PAAm), polyacrylamide graft starch (PAAm-g-St) and starch graft polymer nanocomposite (PAAm-g-St/MMT) was examined using a field-emission scanning electron microscopy (FESEM) (Supra 55 model, Germany) with an air lock chamber in the powdered form. Energy dispersive X-ray (EDX) spectra of platinum-coated starch graft polymer nanocomposite (PAAm-g-St/MMT) were obtained using a Carl Zeiss FESEM analyzer attached with energy dispersive X-ray software X-MAX (Oxford instruments, SDD X-MAX 50, U.K) for elemental analysis.

The ESEM image of the PAAm-g-St/MMT hydrogel in a wet condition was obtained using a ESEM (FEI Quanta 200F, USA). A piece of the PAAm-g-St/MMT hydrogel was taken from the bottle and then directly placed onto a covered ESEM grid. The examination was conducted at a voltage of $15 \mathrm{kV}$, with a working distance of 5-10 mm. 
TEM images of the PAAm-g-St/MMT hydrogels (dried and wet samples) were obtained using a transmission electron microscope (TECHNAI G20, FEI, USA) with an acceleration voltage of $200 \mathrm{keV}$. The image of the wet sample in the transmission mode called wet STEM (Bogner et al. 2005). Prior to TEM image in the dried condition, the PAAm-g-St/MMT hydrogel was completely dried under vacuum. Then the sample was embedded in an epoxy matrix and placed onto a 400 mesh copper grid. For the wet STEM image, the small piece of PAAm-g-St/MMT hydrogel was placed onto the covered TEM copper grid and the wet STEM experiment was conducted with an acceleration voltage of $200 \mathrm{keV}$.

The thermal stability of the hydrogel was characterized by thermogravimetric analysis (TGA) with differential thermogravimetry (DTG) pattern for the dried sample and differential scanning calorimetry (DSC) thermal analysis for the wet sample. The analysis of the dried sample was conducted to determine the decomposition of the nanocomposite polymer backbone, and the analysis for the wet sample was conducted to determine the temperature for breaking of chemical bonds of the hydrogel. The TGA and DTG curves of the dried gel (with and without clay) samples were obtained with the NETZSCH STA 449 F3 Jupiter instrument. Samples were heated from 25 to $800{ }^{\circ} \mathrm{C}$ at a heating rate of $10{ }^{\circ} \mathrm{C} / \mathrm{min}$ under an $\mathrm{N}_{2}$ atmosphere. DSC thermal analysis was carried out using a thermogravimetric analyzer (TA SDT Q-600, Germany) with an aluminum hermetic pan. In that experiment, $10 \mathrm{~mL}$ PAAm-g-St/MMT hydrogel was taken in the aluminum hermetic pan. The sample was heated from 30 to $250{ }^{\circ} \mathrm{C}$ at a heating rate of $2{ }^{\circ} \mathrm{C} / \mathrm{min}$ under an $\mathrm{N}_{2}$ atmosphere.

The TEM and wet STEM examination of hydrogels also provided the evidence of the nanosize of the PAAm-g-St/ MMT hydrogels, and the particle size distribution of clay was analyzed for the confirmation of the nanosize of the clay particles used for synthesis of nanocomposite polymer. A particle size distribution of nanoclay was measured by dynamic light scattering (DLS) techniques, using a Malvern Zetasizer Nano S90 particle size analyzer (Malvern Instruments Ltd., Malvern, UK).

\section{Measurement and analysis}

\subsection{Determination of gelation time}

The rheological properties such as gelation time measurements were estimated by a visual bottle test method (Sydansk 1990). The bottle test method is a semiquantitative measurement of gelation time, and it can also be considered as a fast and inexpensive method to study the gelation kinetics over a wide range of chemical formulations (Dai et al. 2014; Yadav and Mahto 2012). The gelation time of water shutoff gel was considered the period of time when the gelling solution in a code A state turns to a flowing gel code C state (Bai et al. 2015). In this method, the gelation process was investigated at frequent time intervals by tilting the bottles to observe the gel flow behavior under the influence of gravity. The time required for the formation of flowing gel (Code C) was considered as gelation time. Each sample was measured three times to reduce the experimental error.

\subsection{Determination of gel strength}

The gel strength of prepared gel samples was measured using the breakthrough vacuum method as shown in Fig. 1 (Zhao et al. 2015). The prepared gel (approximately $30 \mathrm{~mL}$ ) was transferred into a cuvette. The vacuum pump was then opened and the pipette was placed downward until the end of determination. Finally, the maximum pressure value (gel strength) on the vacuum meter (the breakthrough vacuum) was recorded. All the experiments were conducted three times to ascertain the repeatability of the system, and the average value was used as the gel strength for the sample.

\subsection{Sand pack flooding experiments}

In order to determine the efficiency and plugging capacity of the PAAm-g-St/MMT gel, sand pack flooding experiments were carried out under reservoir conditions. The efficiency and plugging capacity of hydrogel systems were determined by the residual resistance factor $\left(F_{\mathrm{rr}}\right)$ for water and oil and the percentage reduction in permeability, respectively. These studies determined the effect of gel on the absolute permeability of the sand pack, and the water shutoff efficiency was determined using the same procedure as followed by several researchers working in this area (Jia et al. 2011; Salehi et al. 2014; You et al. 2015).

As shown in Fig. 2, the sand pack flooding apparatus consists of a Teledyne ISCO model 500D syringe pump, two injection fluid containers, a stainless steel core holder (diameter-2.8 cm, length-40 cm) and a graduated cylinder to measure the volume of effluent. A $10,000 \mathrm{ppm} \mathrm{NaCl}$ solution (brine) (1.02 cP viscosity) was used to determine the water permeability of the sand pack.

The experimental procedures are as follows: (1) Brine was placed in the injection fluid container and injected into the sand pack by a syringe pump. The injection rate was adjusted by the controller provided with the pump. Brine was injected at constant pressure mode (varying from 20 to 100 psi pressure drop) and 2-3 pore volumes were passed through the sand pack. It was assumed that the sand pack was totally saturated with brine. The effluent brine sample 


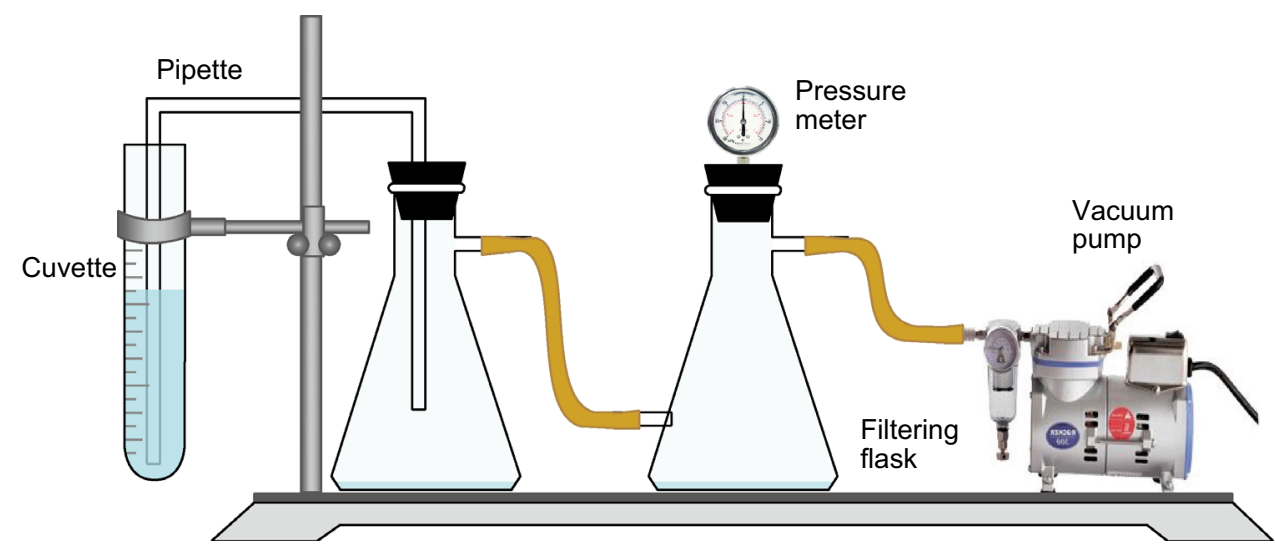

Fig. 1 Setup diagram for measuring gel strength

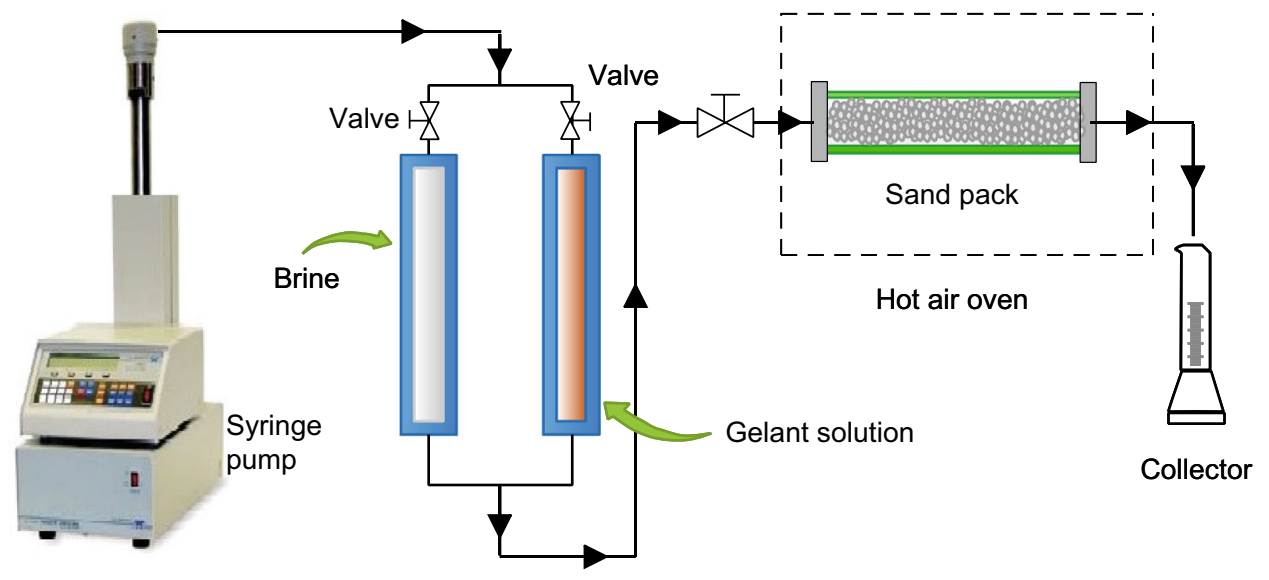

Fig. 2 Setup diagram for sand pack flooding experiments

was collected in a measuring cylinder with time and the absolute permeability of the sand pack calculated using the Darcy equation. The sand pack was saturated by injecting 2-3 pore volumes of brine through it. (2) After brine injection, the oil (crude oil having $14.27 \mathrm{cP}$ viscosity at $303 \mathrm{~K}$ ) was injected into the sand pack to calculate the relative oil permeability $\left(k_{\mathrm{o}}\right)$ of the sand pack at the saturation of connate water and again brine was injected into the sand pack to calculate the relative water permeability $\left(k_{\mathrm{w}}\right)$ of the sand pack at the saturation of residual oil before gel injection. (3) The prepared gelant solution was injected into the sand pack under the same conditions and 2-3 pore volumes of gelant were collected. (4) When the sand pack was saturated with the gelant and the effluent samples of gelant collected in a small glass bottle, the sand pack and the effluent gelant were kept in the hot air oven for a period to insure the gel formation. Considering the time required to form the gel in the bottle test, the sand pack was kept in the hot air oven for three times this gelation time. (5) Then brine and oil was again injected through the sand pack at constant pressure mode (varying from 620 to $1500 \mathrm{psi}$ pressure drop) to find out the relative water permeability and the relative oil permeability after gel injection. It is noted that the experimental fluid (brine or oil) was injected into the sand pack at different flow rates and different pressures. The outlet of the core holder containing the sand pack was kept at atmospheric pressure, and the pressure gradient inside the sand pack is the difference of the injection pressure of the fluid and atmospheric pressure.

The permeability of the sand pack before and after gel treatment was calculated by the linear Darcy equation (Elsharafi and Bai 2016), as shown in Eq. (1):

$k=\frac{Q \mu L}{A \Delta p}=\frac{Q \mu L}{0.78 d^{2} \Delta p}$

where $k$ is the absolute permeability of the sand pack, D; $Q$ is the flow rate, $\mathrm{cm}^{3} / \mathrm{s} ; \mu$ the viscosity of the displacement fluid, cP; $L$ the sand pack length, $\mathrm{cm} ; \Delta p$ is the pressure drop, atm; and $d$ is the sand pack diameter, $\mathrm{cm}$; and the physical meaning of the constant 0.78 is $\pi / 4$.

Normally, the capacity of the gel system for water shutoff or water shutoff efficiency can be evaluated by the 
reduction in permeability of the sand pack after the gel treatment (Chen et al. 2015; Kang et al. 2015; Karimi et al. 2014; Li et al. 2016; You et al. 2015), which is defined as:

$\eta=\frac{k_{\mathrm{w} 1}-k_{\mathrm{w} 2}}{k_{\mathrm{w} 1}} \times 100 \%$

where $k_{\mathrm{w} 1}$ and $k_{\mathrm{w} 2}$ are the water permeability of the sand pack before and after the gel treatment, respectively.

The residual resistance factor $\left(F_{\mathrm{rr}}\right)$ is a measure of permeability reduction and calculated using the following equations (Mohammadi et al. 2015; Salehi et al. 2014):

$F_{\text {rrw }}=\frac{\lambda_{\mathrm{w} 1}}{\lambda_{\mathrm{w} 2}}=\frac{k_{\mathrm{w} 1} \mu_{\mathrm{w} 2}}{k_{\mathrm{w} 2} \mu_{\mathrm{w} 1}}=\frac{k_{\mathrm{w} 1}}{k_{\mathrm{w} 2}}$

$F_{\text {rro }}=\frac{\lambda_{\mathrm{o} 1}}{\lambda_{\mathrm{o} 2}}=\frac{k_{\mathrm{o} 1} \mu_{\mathrm{o} 2}}{k_{\mathrm{o} 2} \mu_{\mathrm{o} 1}}=\frac{k_{\mathrm{o} 1}}{k_{\mathrm{o} 2}}$

where $F_{\text {rrw }}$ is the water residual resistance factor; $F_{\text {rro }}$ is the oil residual resistance factor; $\lambda_{\mathrm{w} 1}$ and $\lambda_{\mathrm{w} 2}$ are water mobility before and after the gel treatment, respectively; $\lambda_{\mathrm{o} 1}$ and $\lambda_{\mathrm{o} 2}$ are oil mobility before and after the gel treatment, respectively; $k_{\mathrm{o} 1}$ and $k_{\mathrm{o} 2}$ are the oil permeability before and after the gel treatment, respectively. The water and oil viscosities are not changed in the whole process, thus $\mu_{\mathrm{w} 1}=\mu_{\mathrm{w} 2}$ and $\mu_{\mathrm{o} 1}=\mu_{\mathrm{o} 2}$ (Mohammadi et al. 2015; Singh and Mahto 2016a).

To evaluate the effectiveness of gel in reducing water permeability in contrast with oil permeability, the ratio of residual resistance factor of water to oil was calculated using the following equation (Mohammadi et al. 2015):

$R R F=\frac{F_{\text {rrw }}}{F_{\text {rro }}}$

where $R R F$ is the ratio of water residual resistance factor to the oil residual resistance factor.

\section{Results and discussion}

\subsection{Characterization of PAAm-g-St/MMT hydrogels}

The XRD patterns of MMT, PAAm-g-St and PAAm-g-St/ MMT hydrogel are plotted in Fig. 3. A basal peak for MMT was recognized at a $2 \theta \sim 6.7^{\circ}$, which represents the diffraction from the periodicity of the stacked silicate layers. The basal peak disappeared when MMT mixed with PAAm. This indicates that clay layers either were exfoliated or too low in content in the polymer (Zolfaghari et al. 2006; Aalaie et al. 2008).

FTIR analyses were utilized to clarify grafting of starch onto polyacrylamide and MMT. The FTIR spectra of MMT, polyacrylamide (PAAm), starch (St) and PAAm-gSt/MMT are shown in Fig. 4. The characteristic vibrational bands of Na-MMT at 3468 and $1638 \mathrm{~cm}^{-1}$ are attributed to

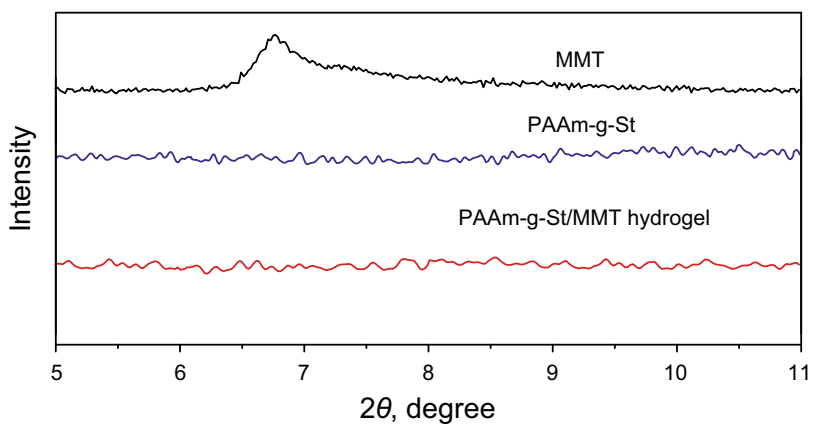

Fig. 3 XRD patterns of MMT, PAAm-g-St and PAAm-g-St/MMT hydrogel

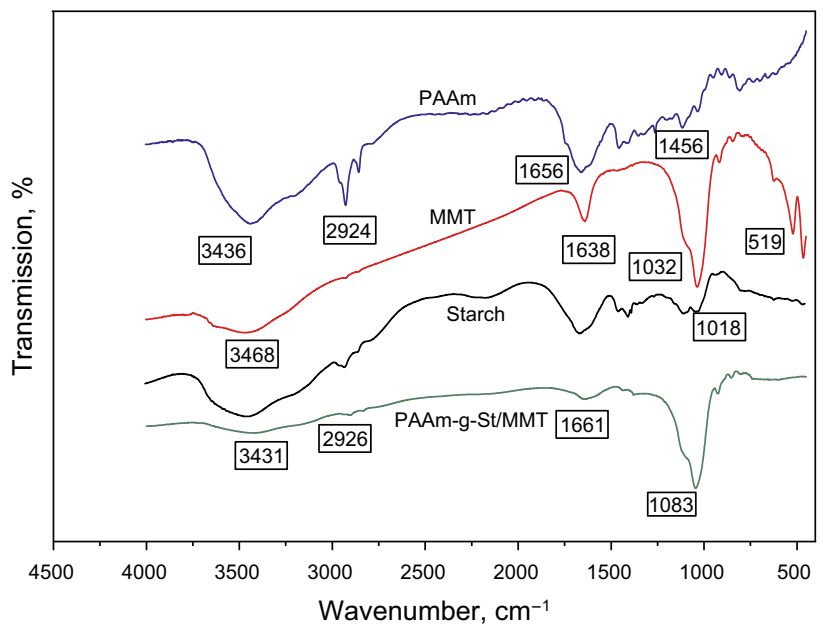

Fig. 4 FTIR spectra of PAAm, MMT, starch and PAAm-g-St/MMT

stretching and bending of $\mathrm{OH}$ groups, respectively. The characteristic absorbance bands at 1032,915 and $519 \mathrm{~cm}^{-1}$ are assigned to bending vibrations of $\mathrm{Si}-\mathrm{O}-\mathrm{Al}$ (octahedral $\mathrm{Al}$ ), $\mathrm{Al}-\mathrm{Al}-\mathrm{OH}$ and $\mathrm{Si}-\mathrm{O}-\mathrm{Si}$, respectively (Eisazadeh et al. 2012; Neppalli et al. 2014). The spectrum of PAAm shows two bands at 3436 and $2924 \mathrm{~cm}^{-1}$, which are due to the N$\mathrm{H}$ stretching vibration of the $\mathrm{NH}_{2}$ group and $\mathrm{C}-\mathrm{H}$ stretching vibrations. The bands at 1656 and $1456 \mathrm{~cm}^{-1}$ are attributed to stretching of $\mathrm{C}=\mathrm{O}$ group in amide and $\mathrm{CH}_{2}$ scissoring, respectively (Singh et al. 2015). For starch, a characteristic absorption peak at $1018 \mathrm{~cm}^{-1}$ is attributed to $\mathrm{C}-\mathrm{O}$ stretching vibration. Characteristic peaks at 1640 and $1080 \mathrm{~cm}^{-1}$ are due to the presence of water and $\mathrm{C}-\mathrm{O}$ stretching of the anhydrous glucose ring (Nakason et al. 2010). However, in the FTIR spectrum of the PAAm-g-St/ MMT, three additional peaks at 3431, 2926 and $1661 \mathrm{~cm}^{-1}$ were observed. These peaks are due to the amine group ($\mathrm{NH})$, stretching of $\mathrm{C}-\mathrm{H}$ bond and amide- $\mathrm{I}(\mathrm{C}=\mathrm{O}$ stretching) of the amide group of graft PAAm chains, respectively (Singh et al. 2015), indicating the presence of MMT and starch. Hence, the FTIR spectra indicate that the PAAm-gSt/MMT was synthesized. 

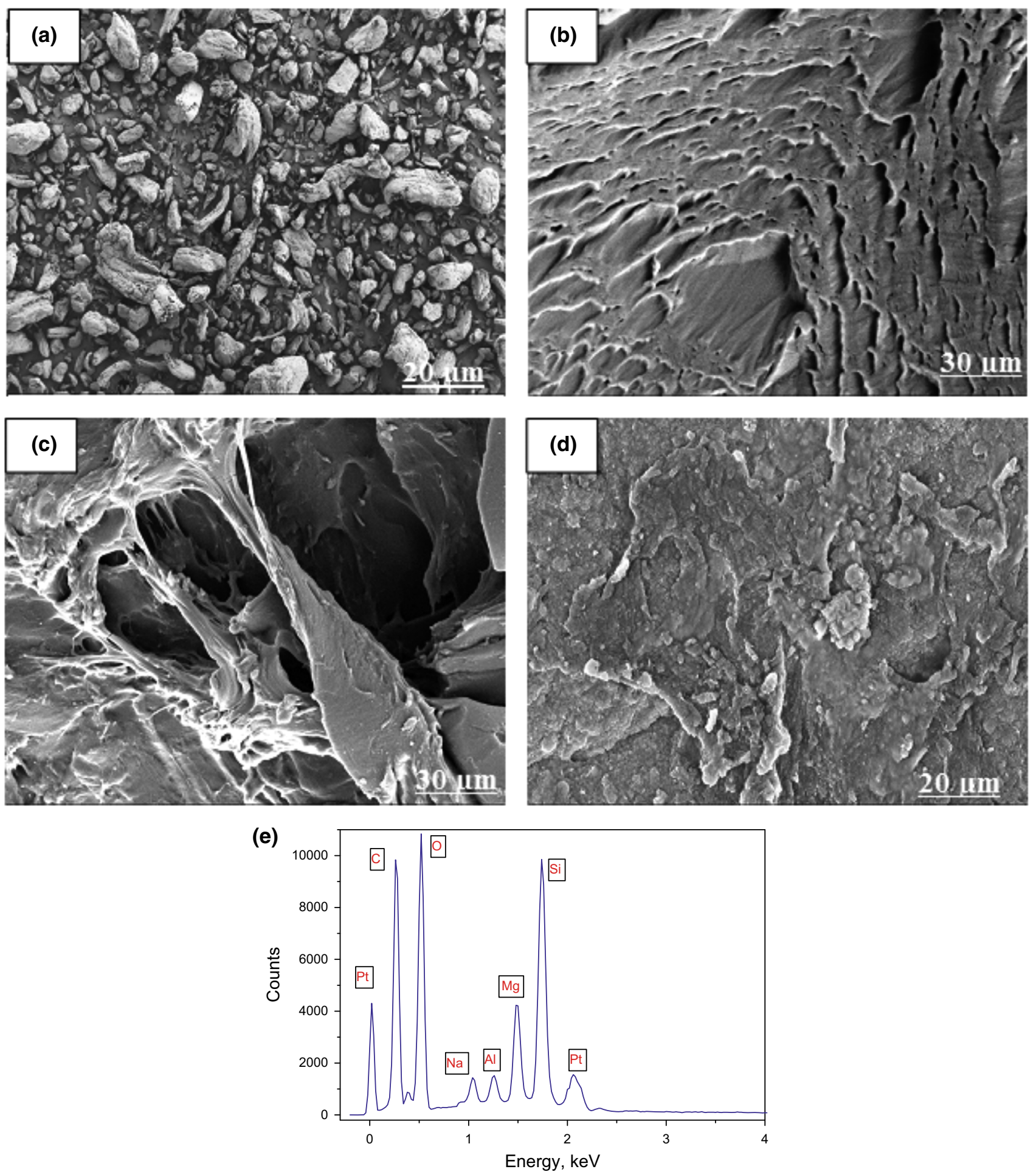

Fig. 5 FESEM images of a starch, b PAAm, c PAAm-g-St and d PAAm-g-St/MMT; and e EDX spectrum of platinum (Pt)-coated PAAm-g-St/ MMT

Field-emission scanning electron microscopy (FESEM) and EDX spectra were used to investigate the morphological features and elemental composition of synthesized PAAm-g-St/MMT. The FESEM images of starch (St), PAAm, PAAm-g-St and PAAm-g-St/MMT are shown in
Fig. 5a-d. It is observed that the starch had a granular morphology and the granular morphology of starch distorted and became a fibrillar structure (Fig. 5c) after being grafted with PAAm (Fig. 5c) (Nakason et al. 2010). Also, the observation of the surface morphology of PAAm-g-St 
and PAAm-g-St/MMT (Fig. 5c, d) indicates after incorporation with MMT, the fibrillar structure of PAAm-g-St was converted to coherent and near co-continuous morphology in PAAm-g-St/MMT (Eisazadeh et al. 2012). In addition, the presence of $\mathrm{Mg}$ (magnesium) and $\mathrm{Si}$ (silica) in the EDX spectrum (as shown in Fig. 5e) of the platinumcoated PAAm-g-St/MMT indicates the nanocomposite has been synthesized.

TEM and FESEM images of the dried PAAm-g-St/ MMT hydrogel are shown in Fig. 6a, b, respectively. The wet STEM and ESEM images of the PAAm-g-St/MMT hydrogel under wet conditions are shown in Fig. 6c, d, respectively. In the TEM image of the PAAm-g-St/MMT hydrogel (Fig. 6a), the black and thin lines are nanoclay. It is clearly visible from Fig. 6a that clay layers were well dispersed within the polymer matrix. Also, it is observed from the surface morphology of the PAAm-g-St/MMT hydrogel (Fig. 6b) that the hydrogel had an undulant surface, which is attributed to the inclusion of nanoclay into the hydrogel. This is also confirmed by the wet STEM image of the PAAm-g-St/MMT hydrogel under wet condition (Fig. 6c). In the wet STEM image of the PAAm-gSt/MMT hydrogel, dark spots represent the nanoclay and the white-gray area the polymer matrix. It is clearly visible from Fig. 6d that nanoclay is well dispersed within the polymer matrix (Mahdavinia et al. 2013). The ESEM image of the PAAm-g-St/MMT hydrogel shows the surface morphology of the hydrogel under wet conditions (Fig. 6d). It is observed that the hydrogel had a uniformly porous mesh-like network structure, which is attributed to the inclusion of nanoclay into the hydrogel.

The particle size distribution of MMT (nanoclay), as shown in Fig. 6e, shows that the size of clay particles varied from 40 to $100 \mathrm{~nm}$. This indicates that the clay used in the synthesis of nanocomposite was in nanosize. The TEM images of the PAAm-g-St/MMT hydrogel (Fig. 6a, d) show the inclusions of nanoclay within the $50 \mathrm{~nm}$ scale. Hence, the size of the PAAm-g-St/MMT hydrogel lies within the nanometer scale.

Thermogravimetric analysis (TGA) and differential thermogravimetry (DTG) patterns of the dried PAAm-g-St/ MMT hydrogel (0.5wt\% PAAm-g-St/MMT, 0.4wt\% crosslinker and $2000 \mathrm{ppm}$ MMT) were evaluated and compared with the conventional polyacrylamide hydrogel $(0.5 \mathrm{wt} \%$ polymer and $0.4 \mathrm{wt} \%$ crosslinker) (Fig. 7). Figure 7 shows a typical TGA thermogram of weight loss as a function of temperature for the PAAm-g-St/MMT hydrogel and the conventional polyacrylamide gel. The thermogram of the polyacrylamide hydrogel shows three main decomposition regimes. The first stage of weight loss occurred up to $100{ }^{\circ} \mathrm{C}$, which may be due to water evaporation. The second stage of weight loss appeared from 100 to $140{ }^{\circ} \mathrm{C}$, which may be attributed to the thermal decomposition of amide and carboxylate side groups of the polyacrylamide (Aalaie et al. 2008; Aalaie and Rahmatpour 2008). On further heating, another weight loss occurred randomly above $140{ }^{\circ} \mathrm{C}$, which suggested the gel network was almost degraded. The thermogram of the PAAm-g-St/MMT hydrogel shows a remarkable extension of degradation temperature, which may be due to the presence of clay in the polymer matrix. The last peak of the DTG curve of PAAm-g-St/MMT hydrogel at around $500{ }^{\circ} \mathrm{C}$ is attributed that the hydrogel was stable below this temperature, which is a remarkable extension of thermal stability over that of the conventional gel system. Hence, the PAAm-g-St/MMT hydrogel system can be used in high-temperature reservoirs.

DSC of the PAAm-g-St/MMT hydrogel under wet conditions was also conducted to estimate the temperature at which the chemical bonds of hydrogel were broken. Figure 8 shows a typical DSC curve of heat flow $(\mathrm{mW} / \mathrm{mg})$ as a function of temperature for the PAAm-g-St/MMT hydrogel under wet conditions. Initially, the hydrogel absorbed heat with a low rate (up to $150{ }^{\circ} \mathrm{C}$ ) and this may be due to the evaporation of some amount of water. This is because water molecules are chemically bounded with polymer and crosslinker. After $150{ }^{\circ} \mathrm{C}$, the hydrogel absorbed the heat with a high rate and a single peak was observed at $178{ }^{\circ} \mathrm{C}$ which indicates that the chemical bond may be broken. Before this temperature, the hydrogel absorbs the heat with an increase in temperature and above this temperature the hydrogel releases the heat. This may be due to the absorbed energy exceeding the energy barrier of breaking chemical bonds, which results in breaking of the gel structure (Liu et al. 2016; Zhao et al. 2013, 2015). So the PAAm-g-St/MMT gel system can be used below $178{ }^{\circ} \mathrm{C}$ for better plugging efficiency in reservoir formations.

\subsection{Effects of graft polymer nanocomposite and crosslinker concentrations}

The polymer and crosslinker concentrations were critical for the performance of the gel network. They directly affect the strength and gelation time of polymer gel systems and thus further affect the plugging capacity and injection depth in high-permeability zones. The effects of polymer and crosslinker concentrations on gelation time and gel strength are shown in Fig. 9. The samples were prepared with different graft polymer nanocomposite concentrations (from $0.4 \mathrm{wt} \%$ to $0.8 \mathrm{wt} \%$ ) and different crosslinker concentrations (from $0.2 \mathrm{wt} \%$ to $0.8 \mathrm{wt} \%$ ) at $90{ }^{\circ} \mathrm{C}$ at a $\mathrm{pH}$ of 8 . It is observed from Fig. 9 that the gelation time increased from 0.75 to $18 \mathrm{~h}$ and the gel strength varied from 0.024 to $0.078 \mathrm{MPa}$ when the nanocomposite polymer and crosslinker concentrations increased from $0.4 \mathrm{wt} \%$ to $0.8 \mathrm{wt} \%$ and from $0.2 \mathrm{wt} \%$ to $0.8 \mathrm{wt} \%$, respectively. Higher graft 

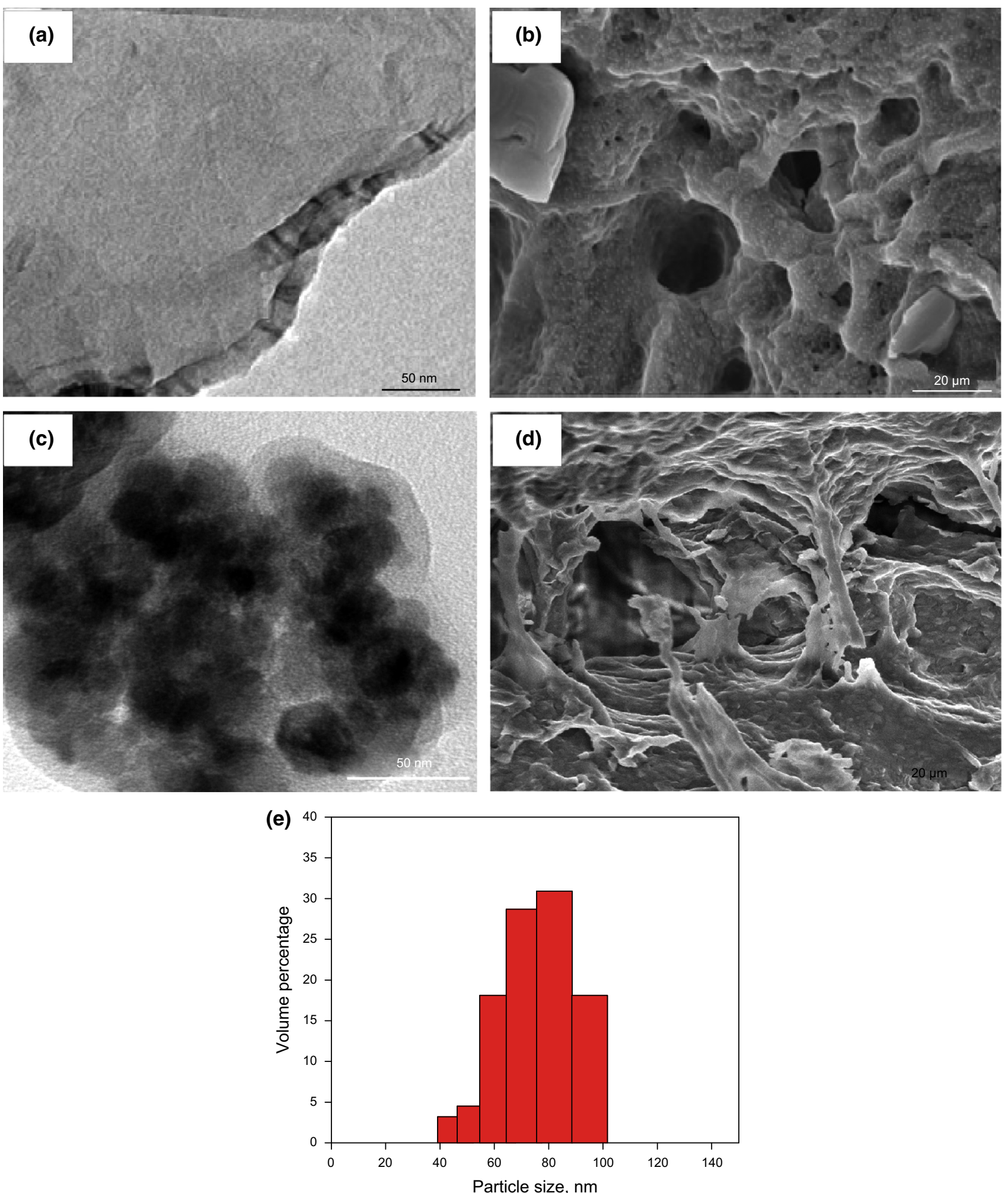

Fig. 6 a TEM and b FESEM images of the dried PAAm-g-St/MMT hydrogel (0.5wt\% PAAm-g-St/MMT and $0.4 \mathrm{wt} \%$ crosslinker). $\mathbf{c}$ Wet STEM and d ESEM images of the PAAm-g-St/MMT hydrogel (0.5wt $\%$ PAAm-g-St/MMT and $0.4 \mathrm{wt} \%$ crosslinker) under wet conditions. e Particle size distribution of MMT (nanoclay) 


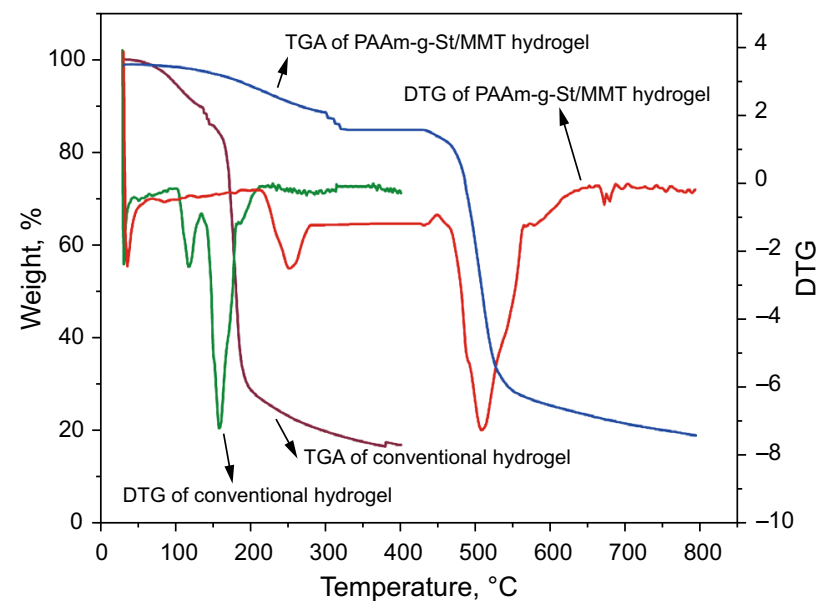

Fig. 7 Thermogravimetric (TG) patterns of the PAAm-g-St/MMT hydrogel $(0.5 \mathrm{wt} \%$ PAAm-g-St/MMT and $0.4 \mathrm{wt} \%$ crosslinker) and the conventional polyacrylamide hydrogel $(0.5 \mathrm{wt} \%$ polyacrylamide and $0.4 \mathrm{wt} \%$ crosslinker)

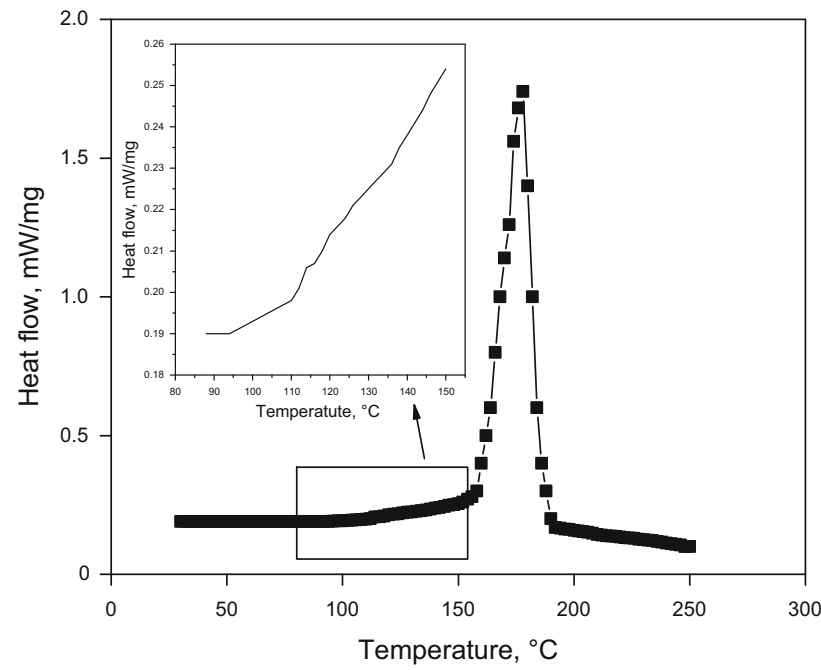

Fig. 8 DSC thermogram of the PAAm-g-St/MMT hydrogel $(0.5 \mathrm{wt} \%$ PAAm-g-St/MMT and $0.4 \mathrm{wt} \%$ crosslinker) under wet conditions

polymer nanocomposite and crosslinker concentrations decreased gelation time and augmented gel strength of the PAAm-g-St/MMT gel system. This may be due to greater availability of negative sites of carboxylate groups, which leads to an increase in the number of bonds between $\mathrm{Cr}^{3+}$ and graft polymer nanocomposite. It is also observed that gel syneresis did not occur even at higher crosslinker concentrations. This may be due to strong interactions between graft polymer chains, crosslinkers and clay (Singh et al. 2015; Zhao et al. 2013).

\subsection{Effect of salt concentration}

The salinity of water has a significant effect on the gel performance. Most polymer gels could not be formed in high salinity ( $\geq 50,000 \mathrm{mg} / \mathrm{L}$ ) reservoirs (Chen et al. 2015) and cannot plug high permeable zones for water shutoff. Table 1 illustrates the effect of $\mathrm{NaCl}$ concentration on gelation time and gel strength of the PAAm-g-St/MMT gel $\left(0.5 \mathrm{wt} \%\right.$ polymer and $0.4 \mathrm{wt} \%$ crosslinker) at $90{ }^{\circ} \mathrm{C}$. Experimental results show that with the addition of $\mathrm{NaCl}$ to the gelant solution, the gelation time decreased and the gel strength increased. This is due to the compression of electrical double layers of polymers with added inorganic salts and the decrease in repulsion forces between the charged groups which allows the reactions to occur more easily (Zhao et al. 2015; Tang et al. 1996). Experimental results also show that the gel has a strong salt tolerance in high salinity reservoirs.

\subsection{Effect of $\mathrm{pH}$}

For different polymer gel systems, different $\mathrm{pH}$ ranges are required to maintain the gel stability. The effect of $\mathrm{pH}$ on the PAAm-g-St/MMT gel $(0.5 \mathrm{wt} \%$ polymer and $0.4 \mathrm{wt} \%$ crosslinker) was investigated in a $\mathrm{pH}$ range of 5.0-9.0 at $90{ }^{\circ} \mathrm{C}$. The gelation time and gel strength of the gel system at different $\mathrm{pH}$ values are listed in Table 2. It is found that the $\mathrm{pH}$ value has no significance effect on the gel strength but affects the gelation time. The gelation time decreased with an increase in the $\mathrm{pH}$ of the PAAm-g-St/MMT gelant solution. This may be due to more $\mathrm{Cr}^{+3}$ complex ions were involved in the crosslinking reaction as the $\mathrm{pH}$ value increased (Karimi et al. 2014). The optimum $\mathrm{pH}$ value was 8.0 for the formation of a rigid gel.

\subsection{Effect of temperature}

The effect of temperature on gelation time and gel strength of the PAAm-g-St/MMT hydrogel $(0.5 \mathrm{wt} \%$ polymer and $0.4 \mathrm{wt} \%$ crosslinker) was investigated at a $\mathrm{pH}$ value of 8.0, and the experimental results are shown in Fig. 10a. The gelation time decreased with an increase in temperature, but the gel strength increased with increasing temperature. This may be due to, either formation of new crosslinking sites during chemical reaction or enhancement of the molecular mobility between nanocomposite polymer molecules and crosslinker molecules at higher temperatures (Zhao et al. 2013).

The gelation time is correlated to temperature according to Arrhenius's equation (Zhao et al. 2013):

$G T=M \exp \left(E_{\mathrm{a}} / R T\right)$

where $G T$ is the gelation time, $\mathrm{h} ; M$ is the frequency factor, $\mathrm{h} ; E_{\mathrm{a}}$ is the activation energy, $\mathrm{kJ} /(\mathrm{molK}) ; R$ is the universal gas constant; and $T$ is the gelation temperature, $\mathrm{K}$.

According to Eq. (6), a plot of the natural logarithm for $G T$ versus $1 / T$ should give a straight line with a slope of $E_{\mathrm{a}} /$ 

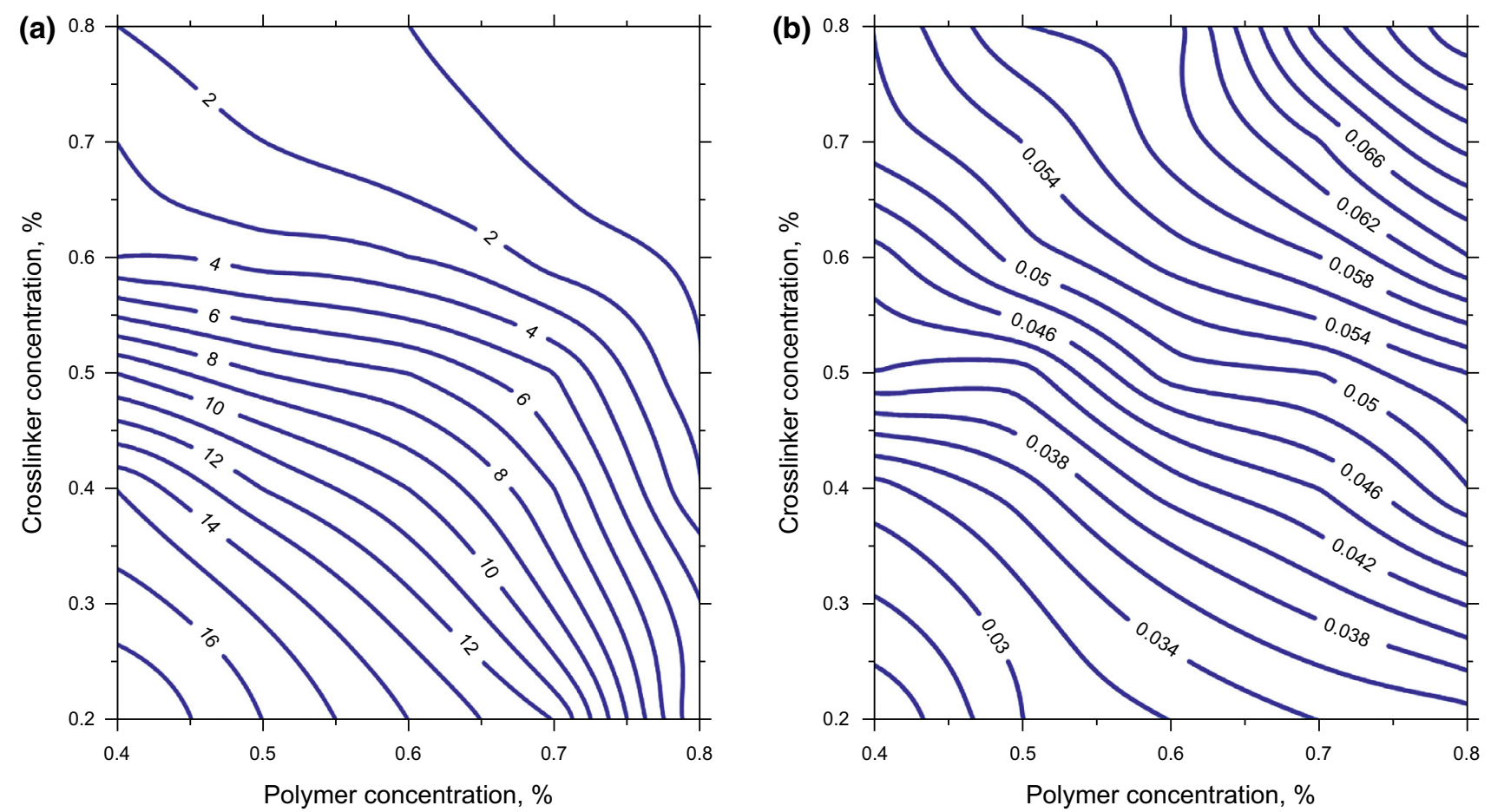

Fig. 9 Contour maps of a gelation time and $\mathbf{b}$ gel strength of the PAAm-g-St/MMT gel system

Table 1 Effect of salt concentration on gelation performance of the PAAm-g-St/MMT hydrogel system $(0.5 \mathrm{wt} \%$ polymer nanocomposite and $0.4 \mathrm{wt} \%$ crosslinker)

\begin{tabular}{lll}
\hline $\mathrm{NaCl}$ concentration, wt $\%$ & Gelation time, $\mathrm{h}$ & Gel strength, MPa \\
\hline 1.0 & 43 & 0.025 \\
2.0 & 25 & 0.028 \\
3.0 & 13 & 0.035 \\
4.0 & 11 & 0.042 \\
5.0 & 9 & 0.049 \\
7.0 & 3 & 0.055 \\
\hline
\end{tabular}

Table 2 Effect of $\mathrm{pH}$ on gelation performance of the PAAm-g-St/ MMT hydrogel system $(0.5 \mathrm{wt} \%$ polymer nanocomposite and $0.4 \mathrm{wt} \%$ crosslinker)

\begin{tabular}{lll}
\hline PH value & Gelation time, $h$ & Gel strength, MPa \\
\hline 5.0 & 43 & 0.034 \\
6.0 & 25 & 0.035 \\
7.0 & 18 & 0.035 \\
8.0 & 13 & 0.035 \\
9.0 & 8 & 0.034 \\
\hline
\end{tabular}

$R$ and an intercept of $\ln M$. The gelation time can be obtained from Eq. (6). Figure 10b shows the Arrhenius relationship between gelation time and gelation temperature for gels prepared using $0.5 \mathrm{wt} \%$ graft polymer nanocomposite (containing $0.2 \mathrm{wt} \%$ clay) and $0.4 \mathrm{wt} \%$ crosslinker at $\mathrm{pH}$ 8.0. The activation energy of this graft polymer nanocomposite gel was measured to be $56.7 \mathrm{~kJ} / \mathrm{mol}$. This relatively low activation energy of graft polymer nanocomposite gel indicates that the gel will form fast and the input energy requirement is low, which results in shorter gelation time at a high temperature (Zhao et al. 2013). This means that the PAAm-g-St/ MMT hydrogel system can be used in applications where moderate gel placement is required.

\subsection{Sand pack flooding experiments}

In sand pack flooding experiments, the concentration of the PAAm-g-St/MMT was set at $0.5 \mathrm{wt} \%$, while the crosslinker concentration varied at $0.4 \mathrm{wt} \%$ and $0.2 \mathrm{wt} \%$ and also in the conventional gel system (polyacrylamide and $\mathrm{Cr}$ (III) acetate gel), the polyacrylamide concentration was $1.0 \mathrm{wt} \%$ and the crosslinker concentration was $0.4 \mathrm{wt} \%$ and $0.2 \mathrm{wt} \%$, respectively.

Detailed experimental results of sand pack flooding are shown in Tables 3 and 4. For the PAAm-g-St/MMT hydrogel system, the residual resistance factor (Table 3) for water and oil was 15.77 and 1.11, respectively. However, for the conventional gel system, the residual resistance factor (Table 3) for water and oil was 8.68 and 1.02, respectively. This indicates that the PAAm-g-St/MMT hydrogel reduced the water relative permeability more than the oil relative permeability. 

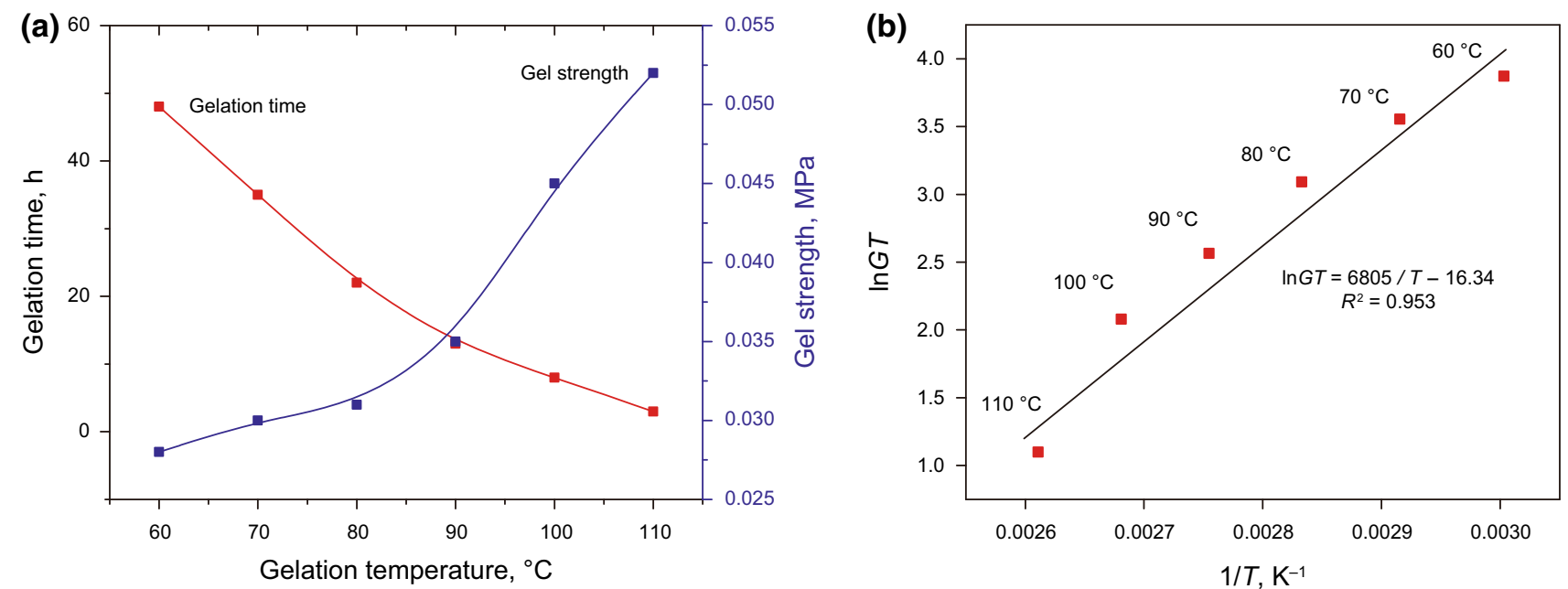

Fig. 10 a Effect of temperature on gelation performance of the PAAm-g-St/MMT hydrogel system. b Arrhenius plot for the PAAm-g-St/MMT hydrogel system $(0.5 \mathrm{wt} \%$ PAAm-g-St/MMT and $0.4 \mathrm{wt} \%$ crosslinker)

Table 3 Injection characteristics of water and oil before and after the injection of PAAm-g-St/MMT gel system and the conventional gel system $^{\mathrm{b}}$ in the sand packs

\begin{tabular}{|c|c|c|c|c|c|c|}
\hline Gel treatment & $\begin{array}{l}\text { Water } \\
\text { injection } \\
\text { rate, } \mathrm{cm}^{3} / \mathrm{s}\end{array}$ & $\begin{array}{l}\text { Pressure } \\
\text { drop, psi }\end{array}$ & $\begin{array}{l}\text { Water permeability } \\
k_{\mathrm{w}}, \mathrm{D}\end{array}$ & $\begin{array}{l}\text { Oil injection } \\
\text { rate, } \mathrm{cm}^{3} / \mathrm{s}\end{array}$ & $\begin{array}{l}\text { Pressure } \\
\text { drop, psi }\end{array}$ & $\begin{array}{l}\text { Oil } \\
\text { permeability } \\
k_{\mathrm{w}}, \mathrm{D}\end{array}$ \\
\hline \multirow{5}{*}{$\begin{array}{l}\text { Before the PAAm-g-St/MMT gel system } \\
\text { injection }\end{array}$} & 0.72 & 20 & 3.43 & 0.05 & 20 & 3.40 \\
\hline & 1.43 & 40 & 3.41 & 0.11 & 40 & 3.75 \\
\hline & 2.17 & 60 & 3.45 & 0.15 & 60 & 3.41 \\
\hline & 2.94 & 80 & 3.51 & 0.21 & 80 & 3.58 \\
\hline & 3.70 & 100 & 3.53 & 0.24 & 100 & 3.27 \\
\hline \multirow{5}{*}{$\begin{array}{l}\text { After the PAAm-g-St/MMT gel system } \\
\text { injection }\end{array}$} & 1.41 & 620 & 0.21 & 0.05 & 620 & 3.40 \\
\hline & 1.77 & 780 & 0.21 & 0.10 & 780 & 3.40 \\
\hline & 2.07 & 880 & 0.22 & 0.13 & 880 & 2.95 \\
\hline & 3.06 & 1250 & 0.23 & 0.19 & 1250 & 3.23 \\
\hline & 3.31 & 1500 & 0.21 & 0.20 & 1500 & 2.72 \\
\hline \multirow{5}{*}{$\begin{array}{l}\text { Before the conventional gel system } \\
\text { injection }\end{array}$} & 0.68 & 20 & 3.24 & 0.05 & 20 & 3.41 \\
\hline & 1.39 & 40 & 3.32 & 0.08 & 40 & 2.73 \\
\hline & 2.38 & 60 & 3.79 & 0.14 & 60 & 3.18 \\
\hline & 2.63 & 80 & 3.14 & 0.18 & 80 & 3.07 \\
\hline & 3.13 & 100 & 2.99 & 0.25 & 100 & 3.41 \\
\hline \multirow{5}{*}{$\begin{array}{l}\text { After the conventional gel system } \\
\text { injection }\end{array}$} & 2.41 & 620 & 0.37 & 0.04 & 620 & 2.73 \\
\hline & 3.02 & 780 & 0.37 & 0.11 & 780 & 3.75 \\
\hline & 3.46 & 880 & 0.38 & 0.13 & 880 & 2.95 \\
\hline & 5.03 & 1250 & 0.38 & 0.19 & 1250 & 3.24 \\
\hline & 5.98 & 1500 & 0.38 & 0.21 & 1500 & 2.86 \\
\hline
\end{tabular}

For the PAAm-g-St/MMT gel system

Average value $k_{\mathrm{w} 1}=3.47, k_{\mathrm{w} 2}=0.22, k_{\mathrm{o} 1}=3.48, k_{\mathrm{o} 2}=3.14, F_{\mathrm{rrw}}=\frac{k_{\mathrm{w} 1}}{k_{\mathrm{w} 2}}=15.77$,

$$
F_{\text {rro }}=\frac{k_{01}}{k_{02}}=1.11, \quad R R F=\frac{F_{\text {rw }}}{F_{\text {rro }}}=14.21
$$

For the conventional gel system injection Average value $k_{\mathrm{w} 1}=3.30, k_{\mathrm{w} 2}=0.38, k_{\mathrm{o} 1}=3.16, k_{\mathrm{o} 2}=3.11, F_{\mathrm{rrw}}=\frac{k_{\mathrm{w} 1}}{k_{\mathrm{w} 2}}=8.68$,

$$
F_{\text {rro }}=\frac{k_{01}}{k_{\text {o2 }}}=1.02, \quad R R F=\frac{F_{\text {rw }}}{F_{\text {rro }}}=8.51
$$

${ }^{a}$ PAAm-g-St/MMT gel system: PAAm-g-St/MMT-chromium (III) acetate nanocomposite hydrogel, including 0.5wt\% PAAm-g-St/MMT and $0.4 \mathrm{wt} \%$ crosslinker

b Conventional gel system: polyacrylamide-chromium (III) acetate hydrogel, including $1.0 \mathrm{wt} \%$ polyacrylamide and $0.4 \mathrm{wt} \%$ crosslinker 
Table 4 A comparison between the graft nanocomposite gel and the conventional gel for water shutoff

\begin{tabular}{|c|c|c|c|c|c|c|c|}
\hline \multirow[t]{2}{*}{ Gel system } & \multirow{2}{*}{$\begin{array}{l}\text { Polymer } \\
\text { concentration, } \\
\text { wt } \%\end{array}$} & \multirow{2}{*}{$\begin{array}{l}\text { Crosslinker } \\
\text { concentration, wt } \%\end{array}$} & \multirow{2}{*}{$\begin{array}{l}\text { Gel } \\
\text { strength, } \\
\text { MPa }\end{array}$} & \multirow{2}{*}{$\begin{array}{l}\text { Porosity of the } \\
\text { sand pack, } \%\end{array}$} & \multicolumn{2}{|c|}{ Water permeability, D } & \multirow{2}{*}{$\begin{array}{l}\text { Permeability } \\
\text { reduction, \% }\end{array}$} \\
\hline & & & & & $\begin{array}{l}\text { Before gel } \\
\text { treatment }\end{array}$ & $\begin{array}{l}\text { After gel } \\
\text { treatment }\end{array}$ & \\
\hline \multirow{2}{*}{$\begin{array}{l}\text { PAAm-g-St/MMT } \\
\text { gel system }{ }^{\text {a }}\end{array}$} & 0.5 & 0.4 & 0.035 & 28.41 & 3.47 & 0.22 & 93.66 \\
\hline & 0.5 & 0.2 & 0.030 & 28.35 & 3.36 & 0.28 & 91.67 \\
\hline \multirow{2}{*}{$\begin{array}{l}\text { Conventional gel } \\
\text { system }^{\text {b }}\end{array}$} & 1.0 & 0.4 & 0.028 & 28.62 & 3.30 & 0.38 & 88.48 \\
\hline & 1.0 & 0.2 & 0.024 & 28.29 & 3.13 & 0.47 & 84.98 \\
\hline
\end{tabular}

${ }^{a}$ PAAm-g-St/MMT gel system: PAAm-g-St/MMT-chromium (III) acetate nanocomposite hydrogel

${ }^{\mathrm{b}}$ Conventional gel system: polyacrylamide-chromium (III) acetate hydrogel

Table 4 lists the percentage of permeability reduction in the sand pack after gel treatments. The results indicates that stronger the gel strength the larger the plugging capacity (permeability reduction) and the plugging capacity of PAAm-g-St/MMT hydrogel is much more than the conventional gel system. Hence, the PAAm-g-St/MMT hydrogel system is more suitable for enhanced oil recovery application than the conventional gel system.

\section{Conclusions}

A novel gel system was developed by polyacrylamide graft starch/clay nanocomposite and chromium acetate (crosslinker). The following conclusions are drawn:

(1) FESEM and XRD revealed that the formation of polyacrylamide graft starch/clay nanocomposite (PAAm-g-St/MMT) hydrogel may be due to strong polymer-clay interaction.

(2) The TGA and DTG results demonstrated that the synthesized PAAm-g-St/MMT hydrogel system had higher thermal stability.

(3) Gel syneresis did not occur even at higher crosslinker concentration.

(4) The gel strength of the developed PAAm-g-St/MMT gel system increased, while the gelation time decreased with the increase in temperature, polymer and crosslinker concentrations in the gelant solution.

(5) The gelation time decreased, but the gel strength increased when the $\mathrm{NaCl}$ concentration increased in the developed hydrogel system.

(6) The change in $\mathrm{pH}$ value had no effect on the gel strength, but the gelation time decreased with an increase in $\mathrm{pH}$ value.

(7) The newly developed PAAm-g-St/MMT hydrogel system had higher plugging capacity than the conventional gel system.

(8) The PAAm-g-St/MMT hydrogel system had high thermal stability and high gel strength, which may be used to control water production in high-temperature reservoirs.

Acknowledgements The authors would like to gratefully acknowledge the Indian Institute of Technology (Indian School of Mines), Dhanbad, India, for providing financial support and necessary laboratory facilities to carry out this work.

Open Access This article is distributed under the terms of the Creative Commons Attribution 4.0 International License (http://crea tivecommons.org/licenses/by/4.0/), which permits unrestricted use, distribution, and reproduction in any medium, provided you give appropriate credit to the original author(s) and the source, provide a link to the Creative Commons license, and indicate if changes were made.

\section{References}

Aalaie J, Rahmatpour A. Preparation and swelling behavior of partially hydrolyzed polyacrylamide nanocomposite hydrogels in electrolyte solutions. J Macromol Sci Part B Phys. 2008;47(1):98-108. doi:10.1080/00222340701746085.

Aalaie J, Vasheghani-Farahani E, Rahmatpour A, Semsarzadeh MA. Effect of montmorillonite on gelation and swelling behaviour of sulfonated polyacrylamide nanocomposite hydrogels in electrolyte solutions. Eur Polym J. 2008;44:2024-31. doi:10.1016/j. eurpolymj.2008.04.031.

Aalaie J, Vasheghani-Farahani E. Swelling behavior of sulfonated polyacrylamide nanocomposite hydrogels in electrolyte solutions: comparison of theoretical and experimental results. Iran Polym J. 2012;21(3):175-83. doi:10.1007/s13726-012-0016-3.

Bai Y, Xiong C, Wei F, Li J, Shu Y, Liu D. Gelation study on a hydrophobically associating polymer/polyethylenimine gel system for water shut-off treatment. Energy Fuels. 2015;29(2):447-58. doi:10.1021/ef502505k.

Behari K, Pandey PK, Kumar R, Taunk K. Graft copolymerization of acrylamide onto xanthan gum. Carbohydr Polym. 2001;46(2):185-9. doi:10.1016/S0144-8617(00)00291-5.

Biswal DR, Singh RP. Characterisation of carboxymethyl cellulose and polyacrylamide graft copolymer. Carbohydr Polym. 2004;57(4):379-87. doi:10.1016/j.carbpol.2004.04.020.

Bogner A, Thollet G, Basset D, Jouneau PH, Gauthier C. Wet STEM: a new development in environmental SEM for imaging nanoobjects included in a liquid phase. Ultramicroscopy. 2005;104(3):290-301. doi:10.1016/j.ultramic.2005.05.005.

Chen L, Zhang G, Ge J, Jiang P, Zhu X, Ran Y, Han S. Ultrastable hydrogel for enhanced oil recovery based on 
double-groups cross-linking. Energy Fuels. 2015;29(11):7196-203. doi:10.1021/acs.energyfuels.5b02124.

Dai C, Zhao G, You Q, Zhao M. A study on environment-friendly polymer gel for water shut-off treatments in low-temperature reservoirs. J Appl Polym Sci. 2014;131(8):40154. doi:10.1002/ app.40154.

Eisazadeh A, Kassim KA, Nur H. Solid-state NMR and FTIR studies of lime stabilized montmorillonitic and lateritic clays. Appl Clay Sci. 2012;67-8:5-10. doi:10.1016/j.clay.2012.05.006.

Elsharafi MO, Bai B. Effect of weak preformed particle gel on unswept oil zones/areas during conformance control treatments. Ind Eng Chem Res. 2012;51(35):11547-54. doi:10.1021/ ie3007227.

Elsharafi MO, Bai B. Influence of strong preformed particle gels on low permeable formations in mature reservoirs. Pet Sci. 2016;13:77-99. doi:10.1007/s12182-015-0072-3.

Ghorai S, Sarkar A, Panda AB, Pal S. Evaluation of the flocculation characteristics of polyacrylamide grafted xanthan gum/silica hybrid nanocomposite. Ind Eng Chem Res. 2013;52(29):9731-40. doi:10.1021/ie400550m.

Hoefner MI, Seetharam RV, Shu P, Phelps CH. Selective penetration of biopolymer profile-control gels: experiment and model. J Pet Sci Eng. 1992;7:53-66. doi:10.1016/0920-4105(92)90008-O.

Jia H, Pu WF, Zhao JZ, Liao R. Experimental investigation of the novel phenol-formaldehyde cross-linking HPAM gel system: based on the secondary cross-linking method of organic crosslinkers and its gelation performance study after flowing through porous media. Energy Fuels. 2011;25:727-36. doi:10.1021/ ef101334y.

Kang WL, Hu LL, Zhang XF, et al. Preparation and performance of fluorescent polyacrylamide microspheres as a profile control and tracer agent. Pet Sci. 2015;12(3):483-91. doi:10.1007/s12182015-0042-9.

Karimi S, Esmaeilzadeh F, Mowla D. Identification and selection of a stable gel polymer to control or reduce water production in gas condensate fields. J Natural Gas Sci Eng. 2014;21:940-50. doi:10.1016/j.jngse.2014.10.026.

Li DX, Zhang L, Liu YM, et al. $\mathrm{CO}_{2}$-triggered gelation for mobility control and channeling blocking during $\mathrm{CO}_{2}$ flooding processes. Pet. Sci. 2016;13(2):247-58. doi:10.1007/s12182-016-0090-9.

Liu Y, Bai B, Wang Y. Applied technologies and prospects of conformance control treatments in China. Oil Gas Sci Technol. 2010;65:859-78. doi:10.2516/ogst/2009057.

Liu Y, Dai C, Wang K, Zhao M, Zhao G, Yang S, Yan Z, You Q. New insights into the hydroquinone (HQ)-hexamethylenetetramine (HMTA) gel system for water shut-off treatment in high temperature reservoirs. J IndEng Chem. 2016;35:20-8. doi:10. 1016/j.jiec.2015.09.032.

Mahdavinia RG, Hasanpour J, Rahmani Z, Karami S, Etemadi H. Nanocomposite hydrogel from grafting of acrylamide onto HPMC using sodium montmorillonite nanoclay and removal of crystal violet dye. Cellulose. 2013;20:2591-604. doi:10.1007/ s10570-013-0004-6.

Maia AM, Silva HV, Curti PS, Balaban RC. Study of the reaction of grafting acrylamide onto xanthan gum. Carbohydr Polym. 2012;90(2):778-83. doi:10.1016/j.carbpol.2012.05.059.

Mansoori Y, Atghia SV, Zamanloo MR, Imanzadeh Gh, Sirousazar M. Polymer-clay nanocomposites: free-radical grafting of polyacrylamide onto organophilic montmorillonite. Eur Polym J. 2010;46:1844-53. doi:10.1016/j.eurpolymj.2010.07.006.

Moghadam AM, Sefti MV, Salehi MB, Koohi AD, Sheykhan M. Effect of nanoclay along with other effective parameters on gelation time of hydro polymer gels. J Macromol Sci Part B Phys. 2012;51(10):2015-25. doi:10.1080/00222348.2012.661667.

Mohammadi S, Sefti MV, Salehi MB, Moghadam AM, Rajaee S, Naderi H. Hydrogel swelling properties: comparison between conventional and nanocomposite hydrogels for water shutoff treatment. Asia-Pacific J Chem Eng. 2015;10(5):743-53. doi:10. 1002/apj.1912.

Nakason C, Wohmang T, Kaesaman A, Kiatkamjornwong S. Preparation of cassava starch-graft-polyacrylamide super absorbents and associated composites by reactive blending. Carbohydr Polym. 2010;81(2):348-57. doi:10.1016/j.carbpol.2010.02.030.

Namazi H, Belali S. Starch-G-lactic acid/montmorillonite nanocomposite: synthesis, characterization and controlled drug release study. Starch. 2015;67:1-11. doi:10.1002/star.201400226.

Neppalli R, Causin V, Marega C, Modesti M, Adhikari R, Scholtyssek S, Ray SS, Marigo A. The effect of different clays on the structure, morphology and degradation behavior of Poly(lactic acid). Appl Clay Sci. 2014;87:278-84. doi:10.1016/ j.clay.2013.11.029.

Pandey S, Mishra SB. Graft copolymerization of ethylacrylate onto xanthan gum, using potassium peroxydisulfate as an initiator. Int J BiolMacromol. 2011;49(4):527-35. doi:10.1016/j.ijbiomac. 2011.06.005.

Qiao R, Zhu W. Evaluation of modified cationic starch for impeding polymer channeling and in-depth profile control after polymer flooding. J Ind Eng Chem. 2010;16(2):278-82. doi:10.1016/j. jiec.2009.09.070.

Salehi MB, Farahani EV, Sefti MV, Moghadam AM, Naderi H. Rheological and transport properties of sulfonated polyacrylamide hydrogels for water shutoff in porous media. Polym Adv Technol. 2014;25:396-405. doi:10.1002/pat.3254.

Sen G, Ghosh S, Jha U, Pal S. Hydrolyzed polyacrylamide grafted carboxymethylstarch (Hyd. CMS-g-PAM): an efficient flocculant for the treatment of textile industry wastewater. Chem. Eng J. 2011;171(2):495-501. doi:10.1016/j.cej.2011.04.016.

Singh R, Kant K, Mahto V. Study of the gelation and rheological behavior of carboxymethyl cellulose-polyacrylamide graft copolymer hydrogel. J Disp Sci. 2015;36(6):877-84. doi:10. 1080/01932691.2014.930793.

Singh R, Mahto V. Preparation, characterization and core flood investigation of polyacrylamide/clay nanocomposite hydrogel system for enhanced oil recovery. J Macromol Sci Part B Phys. 2016a;55(11):1051-67. doi:10.1080/00222348.2016.1238332.

Singh R, Mahto V. Study of the polymer concentration and polymer/ crosslinker ratio effect on gelation time of a novel grafted polymer gel for water shutoff using a central composite design method. Polym Adv Technol. 2016b;27(2):204-12. doi:10.1002/ pat.3622.

Song H, Zhang S. Synthesis and application of starch-graft-poly (AMCo-AMPS) by using a complex initiation system of CS-APS. Carbohydr Polym. 2007;69:189-95. doi:10.1016/j.carbpol.2006. 09.022 .

Strom ET, Paul JM, Phelps CH, Sampath K. A new biopolymer for high-temperature profile control: part 1-laboratory testing. SPE Res Eng. 1991;6(3):360-4. doi:10.2118/19633-PA.

Sydansk RD. A newly developed chromium(III) gel technology. SPE Res Eng. 1990;5(3):346-52. doi:10.2118/19308-PA.

Tang JM, Tung MA, Zeng YY. Compression strength and deformation of gellan gels formed with mono- and divalent cations. Carbohydr Polym. 1996;29:11-6. doi:10.1016/01448617(95)00124-7.

Tongwa P, Nygaard R, Bai B. Evaluation of a nanocomposite hydrogel for water shut-off in enhanced oil recovery applications: design, synthesis, and characterization. J Appl Polym Sci. 2013;128:787-94. doi:10.1002/app.38258.

Vossoughi S, Buller CS. Permeability modification by in situ gelation with a newly discovered biopolymer. SPE Res Eng. 1991;6(4):485-9. doi:10.2118/19631-PA.

Yadav US, Mahto V. Experimental studies, modeling and numerical simulation of gelation behavior of a partially hydrolyzed 
polyacrylamide-hexamine-pyrocatechol polymer gel system for profile modification jobs. Int $\mathbf{J}$ Adv Pet Eng Technol. 2012;1(1):1-16.

Yadav US, Mahto V. Investigating the effect of several parameters on the gelation behavior of partially hydrolyzed polyacrylamide-hexamine-hydroquinone gels. Ind Eng Chem Res. 2013a;52:9532-7. doi:10.1021/ie400488a.

Yadav US, Mahto V. Rheological study of partially hydrolyzed polyacrylamide-hexamine-pyrocatechol gel system. Int J Ind Chem. 2013b;4(1):4-8. doi:10.1186/2228-5547-4-8.

You Q, Wang K, Tang Y, Zhao G, Liu Y, Zhao M, Li Y, Dai C. Study of a novel self-thickening polymer for improved oil recovery. Ind Eng Chem Res. 2015;54(40):9667-74. doi:10.1021/acs.iecr. 5 b01675.

Zhao G, Dai C, You Q, Zhao M, Zhao J. Study on formation of gels formed by polymer and zirconium acetate. J Sol-Gel Sci Technol. 2013;65(3):392-8. doi:10.1007/s10971-012-2951-z.
Zhao G, Dai C, Chen A, Yan Z, Zhao M. Experimental study and application of gels formed by nonionic polyacrylamide and phenolic resin for in-depth profile control. J Pet Sci Eng. 2015;135:552-60. doi:10.1016/j.petrol.2015.10.020.

Zhao JZ, Jia HH, Pu WF, Liao R. Influences of fracture aperture on the water shutoff performance of polyethyleneimine crosslinking partially hydrolyzed polyacrylamide gels in hydraulic fractured reservoirs. Energy Fuels. 2011;25:2616-24. doi:10. 1021/ef200461m.

Zolfaghari R, Katbab AA, Nabavizadeh J, Tabasi RY, Nejad MH. Preparation and characterization of nanocomposite hydrogels based on polyacrylamide for enhanced oil recovery applications. J Appl Polym Sci. 2006;100:2096-103. doi:10.1002/app.23193. 